\title{
Quantitative Survey of 'Montmorency' Tart Cherry Orchard Design in Utah
}

\author{
Zachary T. Brym \\ Biology Department, Utah State University, 4820 Old Main Hill, Logan, \\ UT 84322
}

\author{
Brent L. Black \\ Plants, Soils and Climate Department, Utah State University, 4820 Old \\ Main Hill, Logan, UT 84322
}

Additional index words. canopy spread, canopy volume, Prunus cerasus, sour cherry, trunk cross-sectional area

\begin{abstract}
Montmorency' tart cherry trees (Prunus cerasus L.) are grown commercially in the United States in low-density systems. Commercial tart cherry orchard design has not changed significantly over the past 50 years, but there is some variation from farm to farm in management strategies, including tree spacing, training, and pruning, and the resulting orchard production and turnover. Canopy dimensions and dynamics are important considerations for evaluating and improving orchard management strategies but are not well documented for tart cherry systems. Current orchard design and canopy management strategies were surveyed along a gradient of orchard age across five commercial farming operations in Utah. Trunk cross-sectional area and various canopy dimensions, including spread and volume, were quantified to capture tree size and canopy architecture. The survey indicated a surprising lack of deviation in orchard design in the region over the last several decades with higher variation among blocks within a farm than across farms. As a result, the survey revealed trends in tree growth and canopy structure across the range in orchard ages despite differences in management approaches of the surveyed farms. These trends were useful in illustrating canopy development and space fill. Tree age between 11 and 15 years after planting was determined to represent a transition between establishment and mature growth, where canopies filled available row space and began experiencing senescing canopy structure. Based on the distribution of ages captured in the survey, a significant number of orchards in Utah are at an age range of 11-15 years, perhaps contributing to superior yields per land area reported for the region. The confluence of space-fill and canopy development described in this study highlights a critical period for tart cherry orchard management at the transition of canopy establishment and maturity. These baseline dynamics will provide benchmarks for evaluating strategies for refining and improving orchard management systems for tart cherry in the Intermountain West region.
\end{abstract}

Utah is the second leading tart cherry (Prunus cerasus L.) producing state in the

Received for publication 12 May 2021. Accepted for publication 22 Aug. 2021

Published online 5 October 2021.

Funding for the project was provided by the Utah State University Office of Research and Graduate Studies Doctoral Dissertation Improvement Grant, and by the Utah Agricultural Experiment Station (approved as journal paper number 9020). We thank the grower cooperators from the Utah State Horticulture Association that volunteered their orchards for this research; B. Kluver, J. Florez, and D. Romney for the assistance in field sampling; S.K.M. Ernest, K. Mott, J. Reeve, and E. White for feedback and comments regarding the research project and early drafts of the manuscript.

Current affiliation for Z.T.B.: University of Florida, Tropical Research and Education Center, 18905 SW 280th Street, Homestead, FL 33031

Z.T.B. is the corresponding author. E-mail: brymz@ufl.edu.

This is an open access article distributed under the CC BY-NC-ND license (https://creativecommons. org/licenses/by-nc-nd/4.0/). (e.g., Ferree and Warrington, 2003; Fideghelli et al., 2003; Lauri and Claverie, 2008; QueroGarcia et al., 2017). These broad reviews of tree architecture and management generalize important patterns of tree physiology across production systems, but continuing investigations are important for describing the specific patterns in tree growth for localized management systems. Tart cherry is among the least studied orchard crops for canopy management, with only preliminary development in dwarfing selections (Bors, 2005) and high-density training systems (Hrotko et al., 2008; Palmer, 2011). Trends in commercial design and management of tart cherry orchards specifically for Utah have not been well studied. A better understanding of tree age and canopy dynamics in conventional commercial orchards in Utah could help illustrate temporal trends in orchard design characteristics and identify opportunities for improving management strategies.

We surveyed commercial tart cherry orchards in Utah to describe regional patterns in orchard design characteristics of tree spacing and canopy structure and how these varied with orchard age to assess changes over time. An orchard systems approach was taken for the survey to capture a broad range of factors in orchard design and canopy management. Orchard blocks were selected to represent a gradient of tree age across a series of commercial orchards to explore canopy structure with orchard age and how orchard design may have been altered with successive plantings. We hypothesized that tree density would be greater in younger commercial orchards with associated shifts in tree size and canopy dimension. We quantitatively describe tart cherry orchards in Utah identifying trends in orchard characteristics.

\section{Materials and Methods}

Orchard selection and survey. The research was conducted in Utah Co., UT, in commercial tart cherry orchards (Prunus cerasus 'Montmorency', P. mahaleb). We selected orchard blocks representative of the region's producers and production from five growers among the largest and most established operations in the region. More critically, we chose orchard blocks to approximate a representative distribution of age within each farming operation (Table 1). From this process, six to nine orchard blocks were selected for each of the growers (totaling 38 blocks), which were surveyed in May 2014. We acknowledge that only a small portion of the orchard blocks sampled are juvenile $(<8$ years) and old $(>29$ years), as those age classes are also relatively rare in the region. The "young fruiting" and "mature fruiting" classifications correspond to the fruiting ages around the expected maximum yields as provided by an industry representative (K.A. Papenfuss, unpublished data). Also, a break in the age distribution in the data were notable between 15 and 18 years corresponding to a roughly equal representation for "young fruiting" and "mature fruiting" classes. Orchard blocks were surveyed for in-row spacing, between-row spacing, and tree density. In each 
Table 1. Description of orchard blocks surveyed from five tart cherry farms in Utah County during the 2014 growing season. Orchards were categorized by age into one of four classifications. ${ }^{\mathrm{z}}$ For each participating farm, a total of 7 or 8 orchard blocks were surveyed. With the exception of the oldest blocks, there was at least one block surveyed for each age category from each participating farm.

\begin{tabular}{|c|c|c|c|c|c|c|c|c|}
\hline \multirow[b]{2}{*}{ Farm } & \multirow[b]{2}{*}{ Farm symbol } & \multirow[b]{2}{*}{ Blocks surveyed } & \multicolumn{2}{|c|}{ Age range } & \multicolumn{4}{|c|}{ Age classification $^{z}$} \\
\hline & & & Min & Max & $\mathrm{J}(<8)$ & YF (9-15) & MF (18-22) & $\mathrm{O}(>29)$ \\
\hline$\overline{\mathrm{A}}$ & 0 & 8 & 6 & 22 & 2 & 3 & 3 & 0 \\
\hline $\mathrm{C}$ & $\square$ & 8 & 7 & 30 & 1 & 3 & 2 & 2 \\
\hline $\mathrm{O}$ & $\vec{\Delta}$ & 8 & 7 & 21 & 1 & 4 & 3 & 0 \\
\hline $\mathrm{R}$ & $\boldsymbol{\Delta}$ & 7 & 7 & 29 & 1 & 2 & 3 & 1 \\
\hline $\mathrm{S}$ & $\nabla$ & 7 & 6 & 20 & 1 & 3 & 3 & 0 \\
\hline
\end{tabular}

${ }_{\mathrm{z}} \mathbf{J}=$ juvenile nonfruiting; $\mathrm{YF}=$ young fruiting; $\mathrm{MF}=$ mature fruiting; $\mathrm{O}=$ old.

block, five trees were selected for sampling along a diagonal transect in the interior of the orchard. For each tree, scaffold branches were counted, and trunk cross-sectional area (TCSA) and canopy dimensions were measured leading to estimates of canopy height, spread, and volume.

Canopy dimensions. Canopy dimensions were measured for quadrants defined at $90^{\circ}$ intervals around the tree. Transects were established in the middle of each quadrant that radiated from the trunk diagonally across the row. Along each quadrant diagonal, three points were located corresponding to the top curve, bottom curve, and maximum spread of the canopy. Each point was described by the quadrant diagonal, the distance from the trunk, and the height from the ground. Two more points were recorded for the bottom and top of the canopy in line with the trunk.

Canopy volume estimate. Canopy volume was calculated as the sum of four vertically

$$
\begin{aligned}
& \mathbf{X} \text { - canopy spread measurement }(n=12) \\
& +- \text { canopy height measurement }(n=2)
\end{aligned}
$$

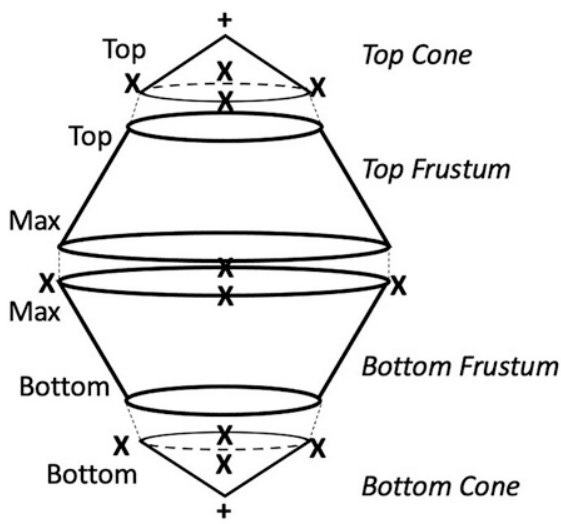

Fig. 1. A diagrammatic representation of the canopy measurements $(n=14)$ and estimation of canopy volume. Canopy height was measured at the lowest and tallest point noted as "+." The remaining canopy spread measurements are noted as "X." Each canopy point was measured in three-dimensional space from the origin of the trunk at ground level as cardinal direction from trunk, horizontal distance, and vertical height. Three tiers of canopy points were taken at the bottom curve, maximum spread, and top curve of the canopy edge. The average canopy radius and height were calculated to estimate two cones and two frustums that were summed to estimate canopy volume. stacked geometric volume estimations, two cones and two frustums (Fig. 1). The average distance from the trunk to canopy edge (radius) for the bottom tier of measurements and the average distance from the bottom tier measurements and the lower canopy measurement at the trunk (height) were estimated as one cone (cone volume $=$ height $\times \pi / 3 \times$ radius $\left.^{2}\right)$. The second cone was calculated similarly for the top tier of measurements and the top canopy measurement at the trunk. The inner sections of the tree canopy were estimated as frustums, or the volume between two ellipses. Each frustum is characterized by a top and bottom ellipse, with their area determined by spread measurements along parallel quadrants, or diameters $\left(d_{1} d_{2}, d_{3} d_{4}\right)$, and the average height across that tier.

Frustum volume $=$ height $\times \pi / 12 \times\left[d_{1} d_{2}\right.$

$$
\left.+d_{3} d_{4}+\left(d_{1} d_{2} d_{3} d_{4}\right)^{1 / 2}\right] .
$$

Data analysis. Correlations among age, TCSA, and canopy dimensions were determined by simple ordinary least squares regression function " $\operatorname{lm}()$ " in $\mathrm{R}$ (Warton et al., 2006). A polynomial function is reported as the best-fit model in cases where it returned a higher $r^{2}$ than the linear function. Data were analyzed at multiple scales: within canopy, individual tree, block, and grower levels. Results were similar across scales and are reported at the block and grower level. Canopy dimensions were compared between growers using PROC GLM in SAS with orchard blocks treated as replicates, with blocking by orchard age classification. Statistical groupings were established using "pdiff" in "LSMeans."

The age-TCSA relationship was evaluated for a breakpoint in canopy development using the "segmented" package in R (Muggeo, 2017). As a complementary analysis, each block was grouped into establishment ( $\leq 13$ years) and mature ( $>13$ years) age classes determined by the results of the breakpoint analysis and evaluated independently for each age class using ordinary least squares regression.

\section{Results and Discussion}

Over the past 50 years, orchard design for many temperate crops such as apple, peach, and sweet cherry has trended to high-density planting systems with intensively managed canopies (e.g., Fideghelli et al., 2003). However, this has not been observed in commercial tart cherry orchards in North America primarily because tart cherry orchards are mechanically harvested using trunk-shake equipment, which constrains tree spacing and lifespan (Affeldt et al., 1988). One component of this survey was to determine both the range and trends in the canopy design characteristics, including tree density and the number of scaffolds per tree. Surveyed orchards ranged from 6 to 30 years old and showed relatively wide variation in tree spacing and planting density ranging from 333 to 633 trees/ha with a mean of 427 trees/ha (Table 2). Tree spacing at some farms remained relatively constant across the range of planting years. For example, farm "C" used constant in-row spacing and only slight $(12 \%)$ variation in between-row spacing, resulting in tree densities ranging from 405 to 452 trees/ha with no consistent trend over time. By contrast, inrow spacing at farm " $\mathrm{A}$ " ranged from 3.7 to $4.6 \mathrm{~m}$, trending toward wider spacing over time, while between-row spacing decreased from a high of $6.1 \mathrm{~m}$ to a low of $5.2 \mathrm{~m}$. This resulted in overall tree density across the sampled orchards at farm " $\mathrm{A}$ " ranging from 422 to 498 trees/ha ( $18 \%$ difference) with no discernable trend in planting density over time. The orchard blocks surveyed on farm "S" had the widest range of tree densities, ranging from 399 to 633 trees/ha, with this farm moving to lower density plantings over time, increasing both in-row and between-row spacings in later planted blocks (Table 2).

By comparison, tart cherry orchards in Michigan have an average tree density of 299 trees/ha (USDA, 2019), trending slightly toward higher planting density. For example, the reported orchards planted in 2018 averaged 316 trees/ha, compared with 281 trees/ ha reported for orchards planted in 2004. The age of orchards in Michigan may also be a factor contributing to differences in yield per land area with Utah. In Michigan, 28\% of orchard acreage is 20 years or older, while $24 \%$ of orchard acreage is $11-15$ years old. We found an estimation of yield for trees in Michigan 10-20 years old at 36-45 kg/tree (Me-Nsope, 2009). For 4 years of data provided at a block level by the farms surveyed in Utah (2012-15) for orchards in the 10-20year age range, average yield was $51 \mathrm{~kg} /$ tree. Three of the 4 years $(2012,2014$, and 2015) exceeded the Michigan estimate with yield at 58,65 , and $52 \mathrm{~kg} /$ tree, respectively. For each 
Table 2. A summary of orchard design parameters of surveyed blocks from five tart cherry farms in Utah County during the 2014 growing season, including in-row tree spacing, between-row tree spacing, tree density, and number of primary scaffolds per tree. Trends are reported to indicate observations made of the data across tree age.

\begin{tabular}{|c|c|c|c|c|c|c|c|c|c|c|c|c|c|}
\hline \multirow[b]{2}{*}{ Farm } & \multicolumn{3}{|c|}{ In row $(\mathrm{m})$} & \multicolumn{3}{|c|}{ Between-row (m) } & \multicolumn{4}{|c|}{ Density (tree/ha) } & \multicolumn{3}{|c|}{ Scaffolds/tree } \\
\hline & Min & Max & Trend & Min & Max & Trend & Min & Mean & Max & Trend & Min & Max & Trend \\
\hline$\overline{\mathrm{A}}$ & 3.7 & 4.6 & $\bar{\uparrow}$ & 5.2 & 6.1 & $\downarrow$ & 422 & 454 & 498 & - & 3.4 & 4.0 & - \\
\hline $\mathrm{C}$ & 4.3 & 4.3 & - & 5.2 & 5.8 & - & 405 & 431 & 452 & - & 2.6 & 3.2 & - \\
\hline $\mathrm{O}$ & 4.3 & 5.2 & - & 5.2 & 5.8 & - & 333 & 374 & 405 & - & 3.0 & 4.0 & - \\
\hline $\mathrm{R}$ & 3.7 & 4.6 & - & 4.9 & 6.7 & - & 376 & 444 & 498 & - & 2.8 & 3.8 & - \\
\hline $\mathrm{S}$ & 3.0 & 4.6 & $\uparrow$ & 4.9 & 5.8 & $\uparrow$ & 399 & 481 & 633 & $\downarrow$ & 3.0 & 4.0 & $\downarrow$ \\
\hline
\end{tabular}

of these years, more than $30 \%$ of the orchard blocks represented in this age class exceeded the $45 \mathrm{~kg} /$ tree estimation for Michigan. Superior yields in Utah on a per land basis may be due in part to the higher planting densities and slightly younger age distribution of trees found in our survey, but are also likely influenced by environmental advantages such as arid climate, higher elevation, and more direct sunlight.

Tree architecture and canopy dynamics were compared among orchard blocks and growers in our survey. With the exception of one grower, there were no major trends in scaffold counts across orchard ages (Table 2). It should be noted that scaffold count is based on the current condition of the orchard, as opposed to initial training system, where fewer scaffolds in older orchards may be expected due to branch aging and die out. Yet, lack of trends in scaffold count with age may indicate relatively good scaffold survival and the relatively few sampled orchard blocks in the oldest age category. To further explore canopy dynamics accounting for variation in tree density and management factors among growers, we focused our remaining analysis on space fill and canopy dimensions per land area (Flore and Kesner, 1995; Palmer, 2011).

Surveyed orchards generally showed that in-row space fill is reached by $11-15$ years (Fig. 2A), which corresponds to the youngfruiting age class originally defined in our selection of orchard blocks. Tree size and timing to space-fill often follow consistent patterns defined across crops (Brym and Ernest, 2018; Deng et al., 2012). In-row space fill greater than 1, indicates overlap of neighboring canopies, and with very few exceptions was observed across mature fruiting and old age class orchards. In contrast, canopies rarely spanned between-row spacing to fully cover the land area of the orchard, saturating around $0.75-0.80$ ha ha $^{-1}$ (Fig. 2B). Evaluated across the surveyed blocks, the maximum in-row space filling of 1.42 occurred at 19 years. Among orchards in this maximum space-filling range (19-21 years), tree density ranged from 354 to 517 trees/ha with the inrow space fill ranging from 1.02 to 1.42 . The range in canopy overlap of mature trees is also influenced by grower management practices such as preferences in pruning and training practices. Further, these older trees were observed to have a range of issues with overall tree health, such as diseased, dead, or removed scaffolds.

Space filling would be expected to occur faster in plantings of higher density affecting tree health and yield (Deng et al., 2012). A recent study reported on densities of 556, 741, and 1481 trees/ha (Cline, 2020). Sixyear-old trees filled space for the high-density in-row spacing of $1.5 \mathrm{~m}$. In this Canada study of young trees, cumulative per tree yields were slightly higher in lower-planting densities in some cases, but cumulative yield per land area was increased at higher densities.

In addition to overall tree health and pruning history, time to in-row space fill and other developmental milestones may be indicative of management intensity such as fertility practices. A previous study with an overlapping set of commercial operations noted significant differences in yield correlated with fertility management, primarily frequency and rate of nitrogen, phosphorus, and potassium (Rowley, 2013). Blocks from farms previously classified as high management intensity (farms " $\mathrm{C}$ " and "O") tend to fall at or above the estimated regression line, whereas growers classified as low intensity (farms "R" and "S") tend to fall below the line (Fig. 2). This would indicate that more intensive management causes more rapid establishment in canopy size greater than chronological age would predict. This is also observed in terms of TCSA (Fig. 3).

Following the evaluation of tree age and space filling in the survey, we further compared tree and canopy size across farms excluding orchards in the juvenile ( $<8$ years) and old ( $>29$ years) age categories. Average tree sizes including tree height, spread, and volume are shown in Table 3. Average tree heights across surveyed blocks differed by farm ranging from 4.7 to $5.8 \mathrm{~m}$. Canopy spread was relatively consistent across farms
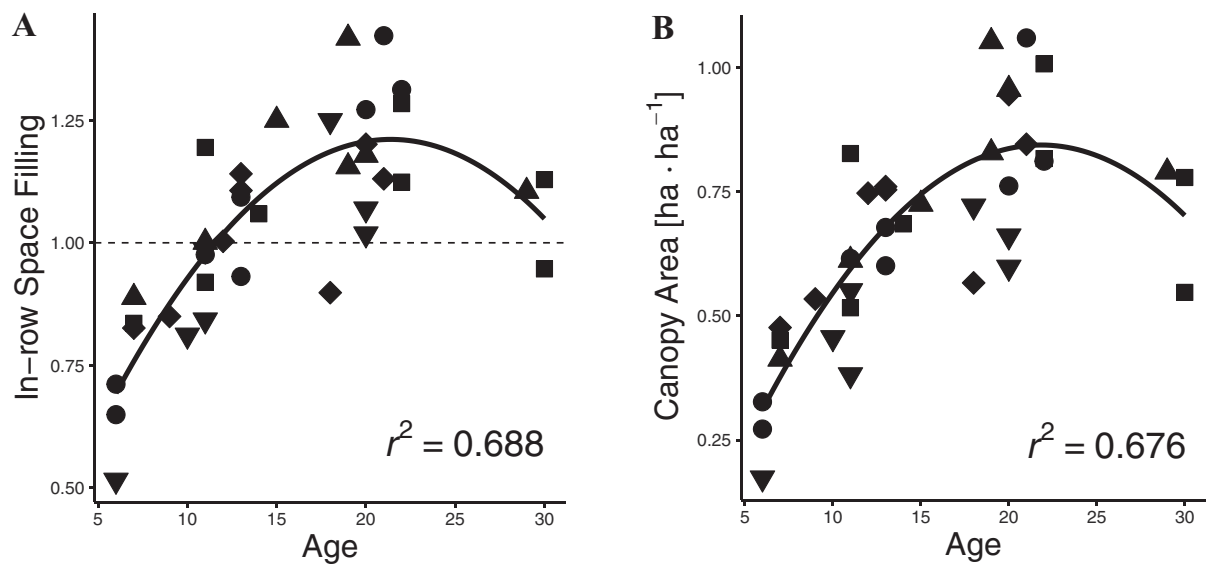

Fig. 2. The relationship between tree age with (A) in-row space filling and (B) canopy area per land area. In-row space fill is represented as a fraction of inrow spacing occupied by canopy diameter. Each data point represents an orchard block and is based on the average value of five randomly selected trees measured in each block. All blocks were 'Montmorency' tart cherry individuals on Mahaleb seedling rootstocks in Utah Co. Growers are distinguished by symbol as per Table $1(\mathrm{~A}=\boldsymbol{\bullet}, \mathrm{C}=\mathbf{\square}, \mathrm{O}=\boldsymbol{\bullet}, \mathrm{R}=\boldsymbol{\Delta}, \mathrm{S}=\boldsymbol{\nabla})$. The bold lines represent the polynomial regression fit corresponding to the reported correlation $\left(r^{2}\right)$. (A) The polynomial equation estimated is $y=-0.002 x^{2}+0.093 x+0.211$. The horizontal dashed line at 1.00 represents the point that canopy spread uses available horizontal canopy space dictated by in-row tree spacing. (B) The polynomial equation estimated is $y=-00212 x^{2}+$ $0.0927 x-0.168$. 


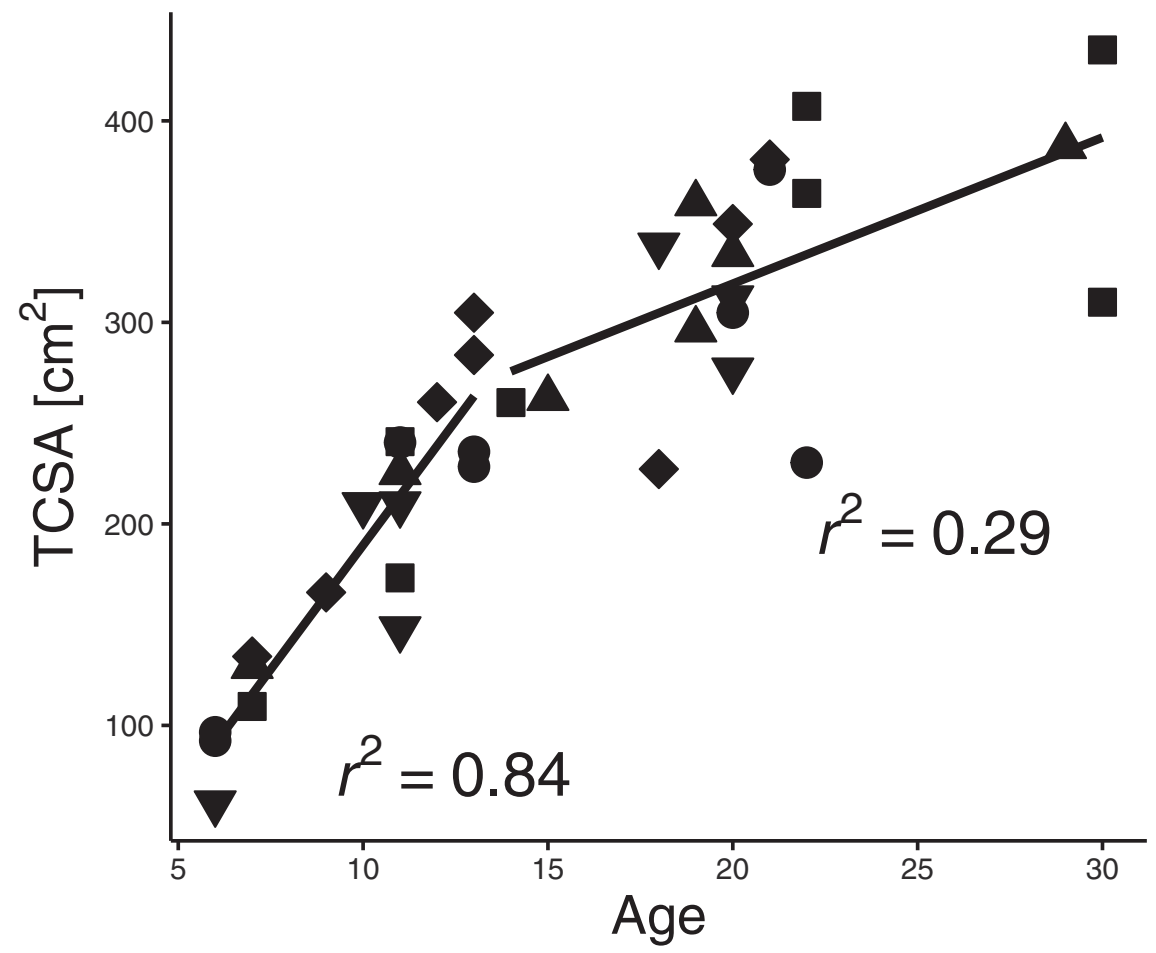

Fig. 3. The relationships between tree age and trunk cross sectional area (TCSA) for 'Montmorency' tart cherries on Mahaleb seedling rootstocks in commercial orchards in Utah Co. Each data point represents an average value for a block with five randomly selected individuals. Growers are distinguished by symbol as per Table $1(\mathrm{~A}=\boldsymbol{\bullet}, \mathrm{C}=\boldsymbol{\nabla}, \mathrm{O}=\boldsymbol{\bullet}, \mathrm{R}=\boldsymbol{\Lambda}, \mathrm{S}=\boldsymbol{\nabla})$. The bold lines represent the regression line corresponding to the reported correlation $\left(r^{2}\right)$. Trees in establishment growth is differentiated from mature growth by a break in the regression estimated at 13 years. The confidence interval $(95 \%)$ for optimal age breakpoint is $10.32-16.25$. The linear equations estimated for age class are: establishment $y=24.7 x-57.2$; mature $y=7.25 x+174$.

except for farm "S," which also had the highest tree densities. As a result, space fill or canopy spread, as a function of in-row spacing, did not differ significantly among farms.

Conventional tart cherry trees are trained and pruned to accommodate trunk-shake harvest, so the minimum branch height is significantly higher than for most other temperate fruit trees. However, the methods used here to quantify individual tree canopy volumes account for differences in branch positions that define both the upper and lower limits of the canopy beyond simple measures of overall tree height and spread. Individual tree volumes also differed for farm "S," due to the variation in overall tree height and the degree of in row canopy overlap. It was noted in Table 2 that tree density decreased for farm "S," where the lowest density planting (399 tree/ha) was also the youngest ( 6 years). When asked about the decision, the grower indicated that trees at the previous higher densities were too vigorous for the spacing and it was challenging to maintain sufficient light penetration with the farm's alternate year pruning system (farm " $\mathrm{S}$ " manager, personal communication).

To compare canopy characteristics and account for tree density, an overall canopy volume was calculated as volume per land area $\left(\mathrm{m}^{3} \cdot \mathrm{m}^{-2}\right)$ resulting in a linear measure $(\mathrm{m})$ indicative of average canopy depth across the orchard. Averaged for each farm, this orchard wide canopy depth ranged from a high of 2.52 $\mathrm{m}$ to a low of $1.42 \mathrm{~m}$ (Table 3 ). The regression model showed canopy depth saturated around 1.76-1.98 m (analysis not shown), with a maximum data point in that range of 2.78 for one 20-year-old orchard block (Table 3 ). This tree age also corresponded with the greatest blockto-block variability in canopy volume per land area $(1.17-2.78 \mathrm{~m})$.

Tree age was strongly correlated with TCSA and measurements of canopy size, including canopy height, canopy spread, and canopy volume, using a negative polynomial relationship across the age range sampled $\left(r^{2}>0.6\right)$. These relationships were surprisingly well correlated despite differences in tree density and management intensity across growers in the survey (Lacointe, 2000; Pilli et al., 2006). Although, the investigation was not designed to reveal the cause of patterns in tree growth, these patterns further informed our quantitative survey of canopy dynamics with respect to tree age and size. Analysis of the relationships among tree age, size, and canopy dimensions per land area are consistent with results of similar relationships per individual tree.

Patterns in canopy development can be influenced by environment and tree age (Archibald and Bond, 2003; Peichl and Arain 2007). To illustrate differences in growth and development between age classifications, we further evaluated the nonlinear relationship of tree age with size and canopy dimensions as two linear relationships corresponding to growth phases that are separated by a statistically determined breakpoint (Fig. 3). The breakpoint in age with TCSA and canopy dimensions was used to quantitatively define the transition point from establishment growth to mature growth, resulting in an estimate of 13 years. Across size and canopy dimensions evaluated in the survey, the transition was determined analytically to range between 11 and 15 years. Interestingly, this statistical breakpoint corresponds closely with the point at which in-row space fill reaches 1 . Therefore, this transition in growth may be driven by space limitations and resulting internal shading (Deng et al., 2012). This transition also correlates with the age when maximum yield potential is first achieved as indicated by regional industry records (Papenfuss, unpublished data) and therefore may also reflect changes in partitioning between vegetative and reproductive growth (Flore and Layne, 1990). The relationship between tree age and TCSA is more variable in older orchards $\left(r^{2}<0.3\right)$ than younger $\left(r^{2}>0.65\right)$. Our survey did not investigate the causes of variability in tree growth and productivity in older orchards, but industry records indicate that some orchard blocks continue to be highly productive beyond the

Table 3. A comparison of tree and canopy size across five tart cherry growers in Utah County for orchard blocks from 13 to 22 years old. Differences between farms were analyzed using PROC GLM in SAS, with orchard blocks treated as replicates, blocked by orchard age classification. Lower case letters indicate significant differences between farms determined by 'pdiff' in 'LSMeans'. The oldest orchard blocks ( $>22$ years) were excluded from the analysis.

\begin{tabular}{lcccccc}
\hline Farm & Blocks & Tree $h t(m)$ & Canopy spread $(\mathrm{m})$ & Space fill (fraction) $)^{\mathrm{z}}$ & ${\text { Tree volume }\left(\mathrm{m}^{3}\right)}^{\text {Canopy vol }(\mathrm{m})^{\mathrm{y}}}$ \\
\hline $\mathrm{C}$ & 3 & 5.81 & $5.14 \mathrm{a}$ & 1.20 & $57.5 \mathrm{a}$ & 2.52 \\
$\mathrm{R}$ & 4 & 5.55 & $5.17 \mathrm{a}$ & 1.25 & $50.2 \mathrm{a}$ & 2.27 \\
$\mathrm{~A}$ & 5 & 5.13 & $4.89 \mathrm{a}$ & 1.34 & $\mathrm{a}$ & 1.99 \\
$\mathrm{O}$ & 5 & 5.13 & $5.22 \mathrm{a}$ & 1.08 & $\mathrm{a}$ & 1.82 \\
$\mathrm{~S}$ & 3 & 4.70 & $3.92 \mathrm{~b}$ & 1.11 & $25.7 \mathrm{~b}$ & 0.0245 \\
$P$ value & & 0.0825 & 0.0042 & 0.1757 & 0.42 & 0.2085 \\
\hline
\end{tabular}

${ }^{\mathrm{z}}$ In-row space fill is represented as a fraction of in-row spacing occupied by canopy diameter.

${ }^{\mathrm{y}}$ Canopy volume is expressed per land area $\left(\mathrm{m}^{3} \cdot \mathrm{m}^{-2}\right)$ resulting in a linear measure $(\mathrm{m})$ indicative of average canopy depth across the orchard. 


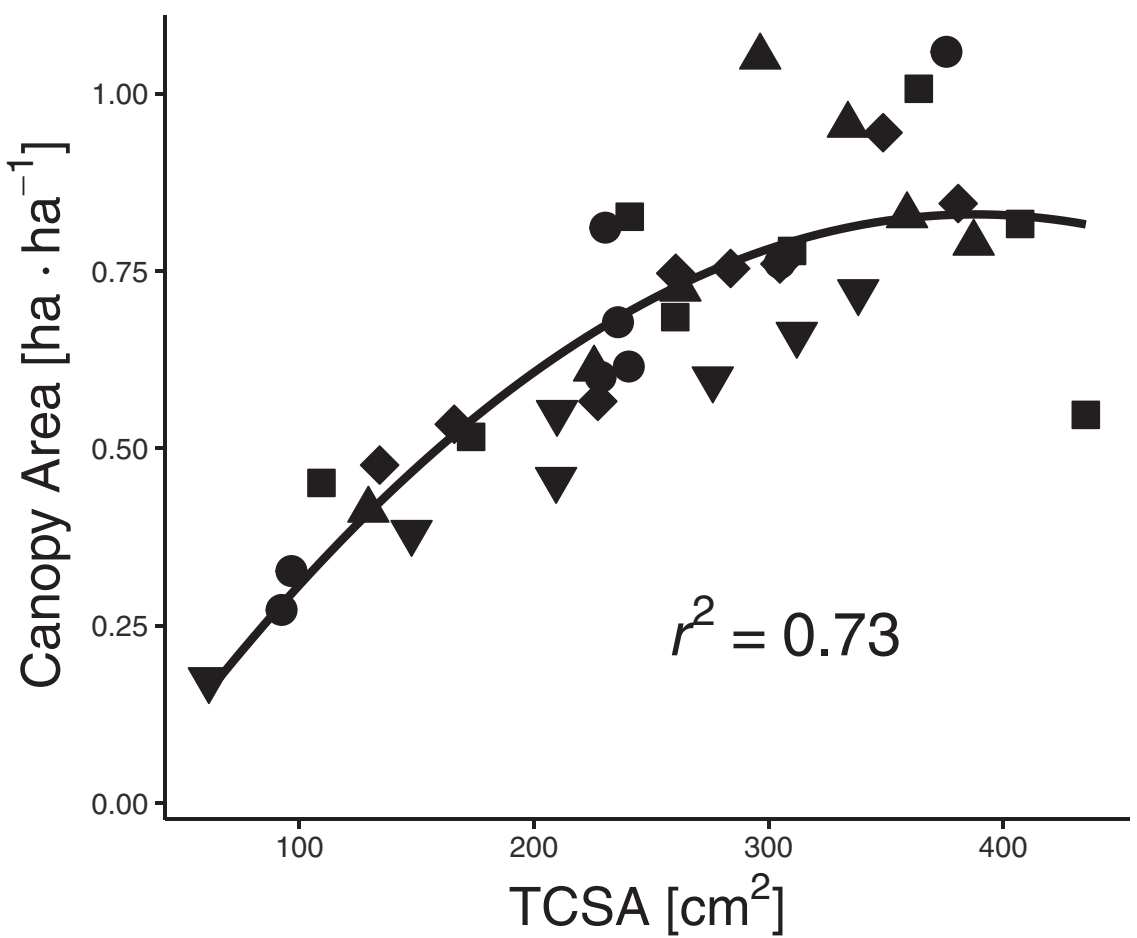

Fig. 4. The relationships of canopy area per land area to trunk cross sectional area (TCSA) for 'Montmorency' tart cherries on Mahaleb seedling rootstocks for various growers in Utah Co. Each block is represented by the average values of five randomly selected individuals. Growers are distinguished by symbol as per Table $1(\mathrm{~A}=\boldsymbol{\bullet}, \mathrm{C}=\mathbf{\square}, \mathrm{O}=\boldsymbol{\bullet}, \mathrm{R}=\boldsymbol{\Lambda}, \mathrm{S}=\boldsymbol{\nabla})$. The bold line represents the regression line corresponding to the reported correlation $\left(r^{2}\right)$ estimated as $y=-0.0000063 x^{2}+$ $0.00489 x-0.118$

optimum orchard age, whereas others experience more rapid decline.

The present study was designed as a survey of orchard design and canopy characteristics and is not ideal for quantifying tart cherry growth dynamics of individual trees (Corelli-Grappadelli and Lakso, 2004; Flore and Layne, 1990). Notably, orchard spacings have been altered over time by some participating growers and there were fewer available orchard blocks in the juvenile and old age categories. However, growth dynamics across orchards of different age can be instructive in understanding tart cherry orchard design and canopy management. The relationship between chronological tree age and canopy characteristics showed a consistent pattern from which there is noticeable variation across blocks and across farms that may vary in management intensity as discussed above (Fig. 2). However, expressing parameters of canopy characteristics as a function of biological age, such as TCSA, showed stronger relationships across orchard blocks perhaps accounting for differences in growth rate of orchards at different ages (Fig. 4). TCSA is a measure of plant growth and the related structure and function of plant architecture (Hinckley et al., 2011; Niklas and Spatz, 2004). TCSA and biomass growth are well correlated, while tree environment, density, and management can influence canopy structure and development (Archibald and Bond, 2003; Deng et al., 2012). The transition in age discussed above (11-15 years) coincides with an inflection point around 250

Yields of marketable fruit are a function of both light interception and partitioning of energy to marketable fruit (Corelli-Grappadelli and Lakso, 2004; Kappes and Flore, 1986). To optimize partitioning to marketable fruit and encourage renewal growth, fruit trees require good light distribution through the canopy (Flore and Layne, 1990; Hrotko et al., 2008). Although tart cherry trees are conventionally pruned to be relatively large trees, pruning focuses on opening up the canopy to improve distribution of light within the canopy (Flore and Kesner, 1995; Lang, 2005; Lauri and Claverie, 2008). We attempted to capture this feature of orchard development through gridded spot measurements of light and fruit sugar content within the tree canopies of these surveyed orchard blocks, but were unable to establish statistically viable relationships (data not shown). Yield information for the orchard blocks were also limited to a block-level value reported for at most 4 years (2012-2015) around the survey effort (2014). High spatial and temporal variability of light more appropriately quantified at the whole-tree or whole-orchard scale than by the in-canopy spot measurements attempted as part of this survey (Hansen, 2018; Harding et al., 2019). Cumulative yields are important to capture overall productivity and seasonal yield variability in perennial fruit crops.

Patterns in tree growth and canopy establishment observed during the survey of $\mathrm{cm}^{2}$ TCSA. penetration and fruit development may be conventional tart cherry reveal reasonable expectations for orchard management and lifespan. Low-density tart cherry trees grow rapidly during establishment for 11-13 years to fill available canopy space with establishment growth varying by as much as 3-5 years around when space filling occurs. Canopy dimensions of height, canopy area, and volume at the growth transition point were estimated to be $5 \mathrm{~m}, 15.5 \mathrm{~m}^{2}$, and $37 \mathrm{~m}^{3}$, respectively. The tree growth transition from establishment to maturity also corresponded to the age at which tart cherry trees are observed to reach optimal productivity in Utah. Further studies are needed to examine the relationship between canopy size and productivity in tart cherry and whether relationships are constant over the range of smaller tree sizes and management strategies.

\section{Conclusions}

Tart cherry trees were surveyed across a range of tree ages to evaluate orchard design and canopy management in Utah. Our survey investigating orchard design across tree age showed consistent trends in tree spacing, canopy management, and space fill patterns helpful in developing and improving orchard systems. Tree spacing varied across orchard blocks surveyed but remained consistent in overall tree density across orchard ages. Tree canopies filled available in-row space around 11-15 years after planting, associated with a clear transition point from rapid establishment growth to diminishing mature growth. This transition was observed in terms of TCSA at $250 \mathrm{~cm}^{2}$. Much greater variability was observed in these relationships for the mature age group. Our data illustrated the transition in canopy development through a survey of various orchard ages but was not able to identify specific drivers of the transition. Space fill, which leads to increased internal shading and a concurrent transition in resource partitioning, appears to occur at a similar transition point for optimal fruiting age. This period of orchard development at 11-15 years represents a critical time for tart cherry orchard management at the transition of canopy establishment and maturity. Our survey also found a distribution of tree ages with a greater abundance of trees in the region at optimal age. The orchard age distribution and orchard design characteristics may contribute to the superior production of tart cherry in Utah on a per land area basis beyond the regional climatic effects. Further, information from this survey may guide regional plans for orchard turnover and replacement and may help identify strategies for improving conventional tart cherry management.

\section{Literature Cited}

Affeldt, Jr., H.A., D.E. Marshall, and G.K. Brown. 1988. Relative dynamic displacements within a trunk shaker clamp. T. Amer. Soc. Ag. Bio. Eng. 31(2):0323-0330. https://doi.org/10.13031/ 2013.30709. 
Archibald, S. and W.J. Bond. 2003. Growing tall vs growing wide: Tree architecture and allometry of Acacia karroo in forest, savanna, and arid environments. Oikos 102(1):3-14, https:// doi.org/10.1034/j.1600-0706.2003.12181.x.

Bors, R.H. 2005. Dwarf sour cherry breeding at the University of Saskatchewan. Acta Hort. 667:135-140.

Brym, Z.T. and S.K.M. Ernest. 2018. Process-based allometry describes the influence of management on orchard tree aboveground architecture. PeerJ 6:e4949, https://doi.org/10.7717/peerj.4949.

Cline, J.A. 2020. Planting density and size-controlling rootstocks influence the performance of Montmorency tart cherry (Prunus cerasus L.). Can. J. Plant Sci. 100(1):16-28, https://doi.org/ 10.1139/cjps-2019-0045.

Corelli-Grappadelli, L. and A.N. Lakso. 2004. Fruit development in deciduous tree crops as affected by physiological factors and environmental conditions. Acta Hort. 636:425-441.

Deng, J., W. Zuo, Z. Wang, Z. Fan, M. Ji, G. Wang, J. Ran, C. Zhao, J. Liu, K.J. Niklas, S.T. Hammond, and J.H. Brown. 2012. Insights into plant size-density relationships from models and agricultural crops. Proc. Natl. Acad. Sci. USA 109(22):8600-8605, https://doi.org/10.1073/pnas.1205663109.

Ferree, D.C. and I.J. Warrington (eds.). 2003. Apples: Botany, production, and uses. CABI, Boston, MA.

Fideghelli, C., A. Sartori, and F. Grassi. 2003. Fruit tree size and architecture. Acta Hort. 622:279-293.

Flore, J.A. and C.D. Kesner. 1995. Chapter 10: Tree canopy management and the orchard environment, principles and practices of pruning and training. In: A. Webster and N. Looney (eds.). Cherries: Crop physiology, production and uses. CABI Publishing, Cambridge, MA.
Flore, J.A. and D.R. Layne. 1990. The influence of tree shape and spacing on light interception and yield in sour cherry (Prunus cerasus cv. Montmorency). Acta Hort. 285:91-96.

Hansen, S.M. 2018. Pruning strategies for high density 'Montmorency' tart cherry. All Graduate Theses and Dissertations. 6879. https:// digitalcommons.usu.edu/etd/6879.

Harding, C., M. Yost, B. Black, G. Cardon, and N. Allen. 2019. Quantifying soil and tree canopy variation in tart cherries for precision irrigation applications. Soil Sci. Soc. Amer. Annual Meeting, 7 Jan., San Diego, CA.

Hinckley, T.M., B. Lachenbruch, F.C. Meinzer, and T.E. Dawson. 2011. A lifespan perspective on integrating structure and function in trees, $\mathrm{p}$. 3-32. In: F.C. Meinzer, B. Lachenbruch, and T.E. Dawson (eds.). Size- and age-related changes in tree structure and function. Springer-Verlag, New York, NY.

Hrotko, K., K. Csigai, L. Magyar, and V. Hrotko. 2008. Productivity of fruiting wood on slender spindle sour cherry trees. Acta Hort. 795:503-508.

Kappes, E.M. and J.A. Flore. 1986. Carbohydrate balance models for 'Montmorency' sour cherry leaves, shoots and fruits during development. Acta Hort. 184:123-127.

Lacointe, A. 2000. Carbon allocation among tree organs: A review of basic processes and representation in functional-structural tree models. Ann. For. Sci. 57:521-533, https://doi.org/10.1051/ forest:2000139.

Lang, G.A. 2005. Underlying principles of high density sweet cherry production. Acta Hort. 667:325-336.

Lauri, P.E. and J. Claverie. 2008. Sweet cherry tree architecture, physiology and management: Towards and integrated view. Acta Hort. 795:605-614.

Me-Nsope, N.M. 2009. Tart cherry yield and economic response to alternative planting densities.
Thesis. Michigan State University. https:// ageconsearch.umn.edu/record/54502.

Muggeo, V.M.R. 2017. Regression Models with Break-Points/Change-Points Estimation. https:// cran.r-project.org/web/packages/segmented/segmented.pdf.

Niklas, K.J. and H.C. Spatz. 2004. Growth and hydraulic (not mechanical) constraints govern the scaling of tree height and mass. Proc. Natl. Acad. Sci. USA 101(44):15661-15663.

Palmer, J.W. 2011. Changing concepts of efficiency in orchard systems. Acta Hort. 903:41-49.

Peichl, M. and M.A. Arain. 2007. Allometry and partitioning of above- and belowground tree biomass in an age-sequence of white pine forests. For. Ecol. Mgt. 253(1-3):68-80, https://doi.org/ 10.1016/j.foreco.2007.07.003.

Pilli, R., T. Anfodillo, and M. Carrer. 2006. Towards a functional and simplified allometry for estimating forest biomass. For. Ecol. Mgt. 237(1-3):583-593, https://doi.org/10.1016/j. foreco.2006.10.004.

Quero-Garcia, J., A. Iezzoni, J. Pulawska, and G. Lang (eds.). 2017. Cherries: Botany, production and uses. CABI, Boston, MA.

Rowley, S.D. 2013. Phosphorus and potassium fertility management for maximizing tart cherry fruit quality and productivity on alkaline soils. Utah State Univ. MS Thesis. Paper 1518. https://digitalcommons.usu.edu/etd/1518.

USDA. 2019. National Agriculture Statistics Service: Michigan Fruit Inventory 2018-2019. https:// www.nass.usda.gov/Statistics_by_State/Michigan/ Publications/Michigan_Rotational_Surveys/ mi_fruit 18/Tart\%20Cherries.pdf.

USDA. 2021. National Agriculture Statistics Service: Quick Stats. 30 Apr. 2021. https://quickstats.nass. usda.gov/.

Warton, D.I., I.J. Wright, D.S. Falster, and M. Westoby. 2006. Bivariate line-fitting methods for allometry. Biol. Rev. Camb. Philos. Soc. 81:259-291. 